ISSN 1130-3743

\title{
DATOS DEL ARTíCUlO
}

Título:

Fecha de recepción:

Fecha de devolución:

Evaluador:
Fecha de envío a evaluación:

Fecha de aceptación definitiva:

\section{Criterios DE Evaluación}

1. Adecuación del título al contenido del trabajo

2. Estructura y contenido del resumen y palabras clave

$\begin{array}{llllllllll}1 & 2 & 3 & 4 & 5 & 6 & 7 & 8 & 9 & 10 \\ 1 & 2 & 3 & 4 & 5 & 6 & 7 & 8 & 9 & 10 \\ 1 & 2 & 3 & 4 & 5 & 6 & 7 & 8 & 9 & 10 \\ 1 & 2 & 3 & 4 & 5 & 6 & 7 & 8 & 9 & 10 \\ 1 & 2 & 3 & 4 & 5 & 6 & 7 & 8 & 9 & 10 \\ 1 & 2 & 3 & 4 & 5 & 6 & 7 & 8 & 9 & 10 \\ 1 & 2 & 3 & 4 & 5 & 6 & 7 & 8 & 9 & 10 \\ & & & & & & & & & \\ 1 & 2 & 3 & 4 & 5 & 6 & 7 & 8 & 9 & 10 \\ 1 & 2 & 3 & 4 & 5 & 6 & 7 & 8 & 9 & 10 \\ 1 & 2 & 3 & 4 & 5 & 6 & 7 & 8 & 9 & 10\end{array}$

3. Estructura, organización y desarrollo del artículo

4. Interés y originalidad en el tratamiento del tema

5. Referencias bibliográficas: relevancia y actualidad

6. Antecedentes: revisión de la literatura

7. Metodología del trabajo

8. Resultados y conclusiones: aportación al conocimiento científico

9. Aspectos formales: redacción, claridad, rigor conceptual

10. Valoración global

\section{VALORACIÓN FINAL}

A. Publicable tal como está (corrigiendo algún aspecto de forma señalado)...

B. Publicable, con las correcciones y mejoras señaladas.

C. No publicable, por razones señaladas

Modificaciones, correcciones, sugerencias (en caso de A o B)

Fundamentos de la resolución (en caso de C)

Anotaciones para el director, de uso exclusivo

Universidad de Salamanca. Facultad de Educación.

Departamento de Teoría e Historia de la Educación.

C/ Paseo de Canalejas, 169. 37008 Salamanca.

Teléfono: 923294 630, extensión 3391, agd@usal.es 